\title{
Ornamental feathers in Cretaceous Burmese amber: resolving the enigma of rachis-dominated feather structure
}

\author{
Lida Xing ${ }^{1,2+}$, Pierre Cockx ${ }^{3,4+}$, Ryan C. McKellar ${ }^{3,4,5^{*}}$ (D) and Jingmai O'Connor ${ }^{6}$
}

\begin{abstract}
Over the last 20 years, compression fossils of feathers surrounding dinosaurs have greatly expanded our understanding of the origin and evolution of feathers. One of the most peculiar feather morphotypes discovered to date are rachis dominated feathers (RDFs), which have also been referred to as proximally ribbon-like pennaceous feathers (PRPFs). These elongate feathers are only found in the tail plumage, typically occurring in pairs with both streamer (not proximally ribbon-like) and racket-plume morphologies recognized. Here we describe a large sample set of isolated and paired RDFs from Upper Cretaceous Burmese amber ( $99 \mathrm{Ma})$. Amber preserves the finest details of these fragile structures in three dimensions, demonstrating that RDFs form a distinct feather morphotype with a ventrally open rachis, and with significant variability in pigmentation, microstructure, and symmetry.
\end{abstract}

Keywords: Enantiornithes, Confuciusornithiformes, Fossil feather, Myanmar, Ornamental feather

\section{Introduction}

The discovery of numerous feathered dinosaur specimens in China (e.g., Ji and Ji 1996; Ji et al. 1998; Chen et al. 1998; Xu et al. 2014) and other regions (e.g., van der Reest et al. 2016) has greatly improved knowledge of early dinosaur feathers and their evolution, displaying a wide range of feather types (Zhang et al. 2006). Some appear comparable to those that exist in modern birds while others are more unusual. One of the most curious morphotypes reported to date is the rachis dominated feather (RDF), which has been documented in two lineages of basal birds, the Confuciusornithiformes and Enantiornithes (O'Connor et al. 2012), but appears absent in living birds. Similar feathers may also be present in the Scansoriopterygidae, judging from the traces of tail feathers preserved in the holotype of Epidexipteryx hui (Zhang F.C. et al., 2008). Although early interpretations of these feathers were confused by incompleteness and poor preservation (Zhang and Zhou 2000), recent discoveries of more complete RDF compression fossils

\footnotetext{
* Correspondence: ryan.mckellar@gov.sk.ca

†Lida Xing and Pierre Cockx contributed equally to this work.

${ }^{3}$ Royal Saskatchewan Museum, Regina, Saskatchewan S4P 4W7, Canada

${ }^{4}$ Biology Department, University of Regina, Regina, Saskatchewan S4S OA7,

Canada

Full list of author information is available at the end of the article
}

suggested that this unique, extinct morphotype may have been derived from a typical pennaceous feather (O'Connor et al. 2012; Wang et al. 2014). The earliest known traces consisted of poorly preserved rachises, which appear 'ribbon-like', and the first complete feathers described were racket-plumes (pennaceous vanes distally with 'ribbon-like' base). The term PRPF (proximally ribbon-like pennaceous feather) led to at least one distinct morphology being lumped together with RDFs due to similarly 'ribbon-like' proximal portions (Xu et al. 2010). However, recent discoveries of fully pennaceous RDFs suggest that this morphotype may be a specialized form of normal pennaceous feather. This hypothesis is further supported by the discovery of a medial stripe in the unmodified remiges and rectrices of ornithothoracines (Wang et al. 2014, 2015) - a feature that was previously thought to be restricted to elongate RDFs in tail plumage. Furthermore, morphological differences in enantiornithines and confuciusornithiforms suggest that a pair of elongate racket-plume tail RDFs evolved more than once (Wang et al. 2014).

Understanding of RDF morphology has been strongly hindered by their preservation as compressed carbon films in sedimentary rocks: limited morphological details can be observed in this setting. A lack of topography has 
led to difficulties in establishing three-dimensional structure and areas of overlap, and the finest morphological features are not consistently preserved. The medial stripe is an excellent example of this problem. The line that runs down the middle of the rachis in RDFs has been viewed as a groove (Wang et al. 2014), supported by the discovery of slightly three-dimensional impressions of RDFs alongside a juvenile enantiornithine from Brazil (Carvalho et al. 2015), like the depression seen on the ventral surface of modern flight feathers (Lucas and Stettenheim 1972). The medial stripe has also been interpreted as a thickened ridge of keratin within a hollow, tubular rachis (e.g., Zheng et al. 2009), or a complete rachis equivalent (e.g., Zhang Z. et al., 2008; Zhang F.C. et al., 2008). Isolated Cretaceous feathers in amber from Canada, France, Japan, Lebanon, Myanmar, Spain and the USA (Schlee and Glöckner 1978; Grimaldi and Case 1995; Grimaldi et al. 2002; Delclòs et al. 2007; Perrichot et al. 2008; McKellar et al. 2011; Peñalver et al. 2017), and skeletally associated feathers in amber (Xing et al. 2016a, b, 2017) have recently become a valuable supplement to the compression fossil record of feathers. Amber preserves three-dimensional specimens with microstructure and pigmentation (Thomas et al. 2014) and has the potential to clarify problematic structures and reveal fine morphological details unlikely to preserve in compression fossils. Here we describe 31 Burmese amber samples that contain feathers, which elucidate the RDF morphology and its range of variability. Twenty-five specimens contain diagnostic RDFs (including ten pairs of feathers), and eight fragmentary feathers are less conclusive. The feathers reveal an open rachis with no pith cavity like that uniformly present in previously described feathers entombed in amber, differing significantly from previous hypotheses regarding RDF structure based on compression fossils.

\section{Methods}

The material originates from the Cretaceous amber deposit of Noije Bum, in the Kachin state of Myanmar, which is the main source of amber in the country. Radiometric dating performed with zircons in the matrix associated with amber has provided an estimated age of the deposit at $98.8( \pm 0.62) \mathrm{Ma}$ (Shi et al. 2012). This amber is frequently referred to as "Burmese amber" and has been mined for centuries. It is the most productive source of Cretaceous amber inclusions and is considered as one of the most important deposits for the study of Cretaceous terrestrial life (Grimaldi et al. 2002; Ross et al. 2010). More recently, its exceptional preservation potential for vertebrate inclusions was highlighted by the discovery of remarkable inclusions, such as primitive birds (Xing et al. 2016a, 2017) and a coelurosaur tail (Xing et al. 2016b). The chemical composition and botanical inclusions found in this amber suggest that the botanical source of the resin is among the Araucariaceae or the Dipterocarpaceae (Ross et al. 2010).

Observations were performed using a stereomicroscope (Leica MZ12.5) and a compound microscope (Olympus CH30). Macrophotographs were prepared at the Royal Saskatchewan Museum (Regina, Saskatchewan, Canada) using a Visionary Digital photography station consisting of a Canon EOS 5D DSLR camera equipped with Canon MP-E $65 \mathrm{~mm}$ or EF-50 $\mathrm{mm}$ lenses. The pictures obtained at various focal lengths were subsequently combined using Helicon Focus 5.3.14 software, to achieve an increased depth of field. Microphotographs were taken with a Sony NEX-5 camera attached to the Olympus CH30 compound microscope, as well as with a Canon EOS Rebel T6i attached to the Leica MZ12.5. Because of the amber thickness, some of the samples were placed in a glycerin bath to improve their light transmission and remove optical distortions. Flow lines within the amber were observed in greater detail using UV light $(395 \mathrm{~nm})$.

SEM observations were made at the University of Alberta, Department of Earth and Atmospheric Science (Edmonton, Alberta, Canada), using a Zeiss Sigma 300 VP-FESEM operated in variable pressure mode with uncoated samples. These observations were supplemented with backscatter and energy dispersive X-ray spectroscopy to examine the composition and preservation of the feathers.

The institutional abbreviation "DIP" stands for: Dexu Institute of Palaeontology, Chaozhou, China; "MCAC" stands for Mingchuan Amber Center, Beijing, China; "RSKM" stands for Royal Saskatchewan Museum, Regina, Canada. Feather terminology follows that of Lucas and Stettenheim (1972), and Prum (1999) (specifically the anatomical orientations for the feather and follicle: the posterior margin of the follicle corresponds to the ventral surface of the feather in the samples analyzed); while pigmentation and feather microstructure largely follow the terminology of Dove (2000).

\section{Results}

\subsection{General features of RDFs}

It is possible to make some generalizations about the observed structures and their variability within the amber specimen set. These general observations are followed by a more detailed description of each sample (in Section 3.2).

\subsubsection{Rachis morphology}

Compression fossils of RDFs have led to the interpretation that these feathers represent modified pennaceous feathers comparable to modern bird feathers but with an enlarged rachis (thus rachis-dominated) (O'Connor et al. 2012), implying a broad, hollow rachis with a crescentic cross-section. However, preservation of a wide range of 
RDF morphologies in amber (Fig. 1a-c) reveals that unlike modern feathers or previous hypotheses based on fossils, RDFs have an exposed rachidial ridge surrounded by two laminae of fused and unfused barb ridges, forming a $\mathrm{C}$-shaped section opening ventrally (Figs. 1 and 2). Put in simpler terms, the rachis is open on the underside of the feather, and it lacks a pith cavity filled with spongy tissue. These general features are consistent among all amber samples analyzed, but variability exists in the finer details of the rachises. The paper-thin fused barbs, together with the rachial ridge, form the medially striped rachis preserved in compression fossils (Wang et al. 2014; Carvalho et al. 2015). In some specimens, the rachidial ridge is present as a faint or sporadic line, while others have a pronounced, blade-like ridge running the entire length of the rachis (e.g., Fig. 1e-g). Despite this variability, all RDFs can be clearly distinguished from normal flight feathers with a complete, pith-filled rachis, because the latter samples have milky amber or mineral infills within their rachises (e.g., Xing et al. 2016a: Fig. 2a-d), that are apparent in both cross-sectional and external views.

Apical morphology of the rachis varies widely within the specimen set, but in most RDFs, the distal ends of the laminae taper progressively. Some of the feathers taper to just the rachidial ridge apically-in these samples the rachis is similar in width to the adjacent barb rami along its distal length (Fig. 2a). In contrast,

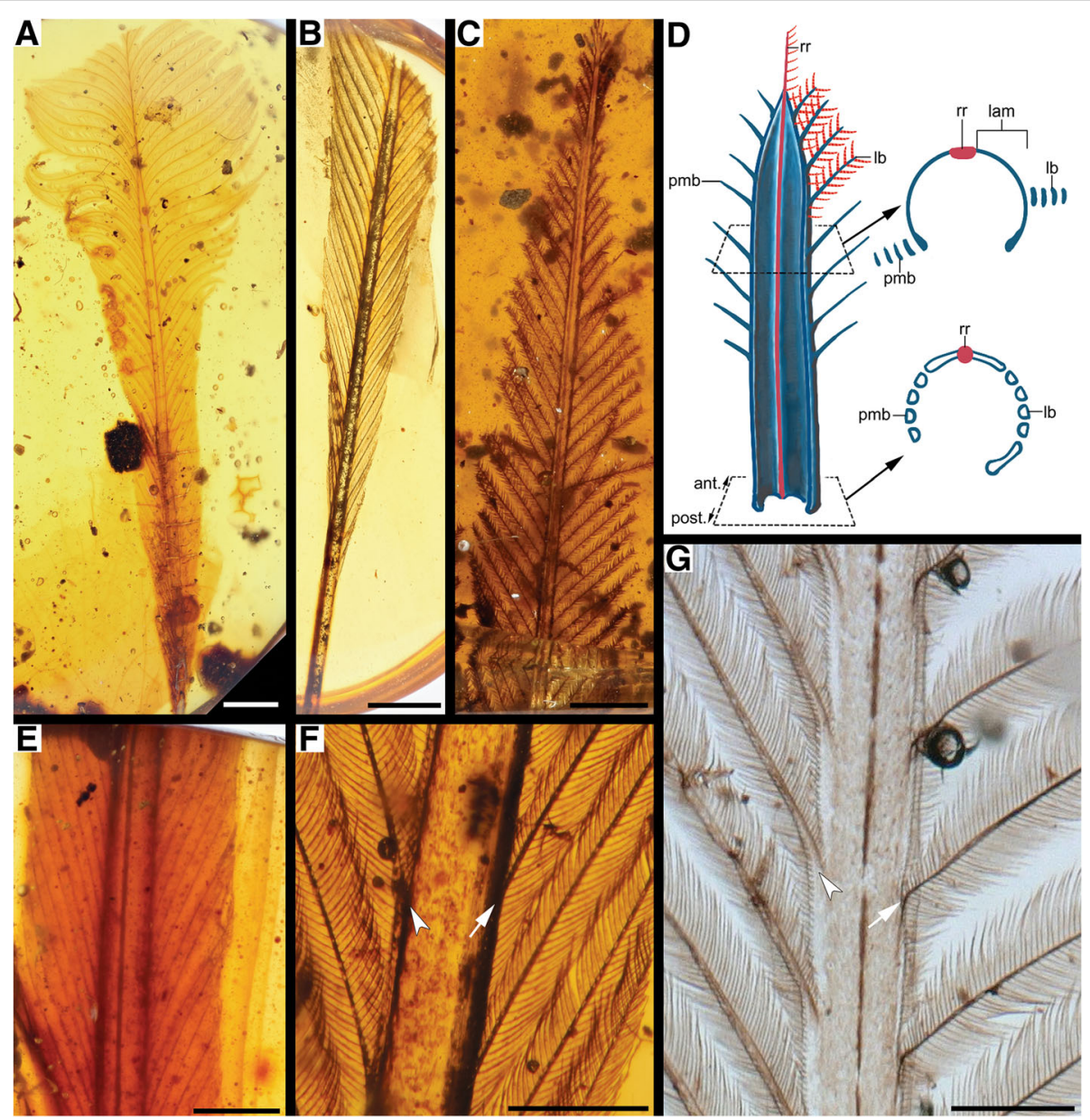

Fig. 1 Morphological diversity and rachis structure. RDFs exhibit at least three general outlines: a with barbs that appear to extend all the way down rachis, one of the two feathers in DIP-V-16186; b with naked rachis basally, DIP-V-16208 overview; c with more pointed apices and narrower vanes, one of the two feathers in DIP-V-16186. The general structure of all RDFs shares some common features: $\mathbf{d}$ diagram of RDF indicating rachidial ridge (dark red), and fused and unfused barb ridges making up rachis (blue), with barbule distribution indicated only on right side of feather apex (pale red), and with cross-sections showing branching pattern of barbs within vaned section of RDF (upper section), and tissue generation at follicle (lower level) required to produce barbs at posterior margin, or along lateral margin of rachis (right side vs. left side of each section, respectively). Rachidial ridge variants include: e prominent ridge throughout length, DIP-V-17138; f faint, DIP-SY-06231; g or even sporadic, MCAC-0322. Arrowheads in $\mathbf{f}$ and $\mathbf{g}$ indicate barbs attached to posterior margin of rachis, while arrows indicate those attached to lateral surface. Abbreviations: ant - anterior, lam - lamina, lb. - lateral barb, pmb - posterior margin barb, post - posterior, rr - rachidial ridge. Scale bars $=2 \mathrm{~mm}$ in $(\mathbf{a}, \mathbf{b}, \mathbf{c}$, e and $\mathbf{f}) ; 0.5 \mathrm{~mm}$ in $(\mathbf{g})$ 


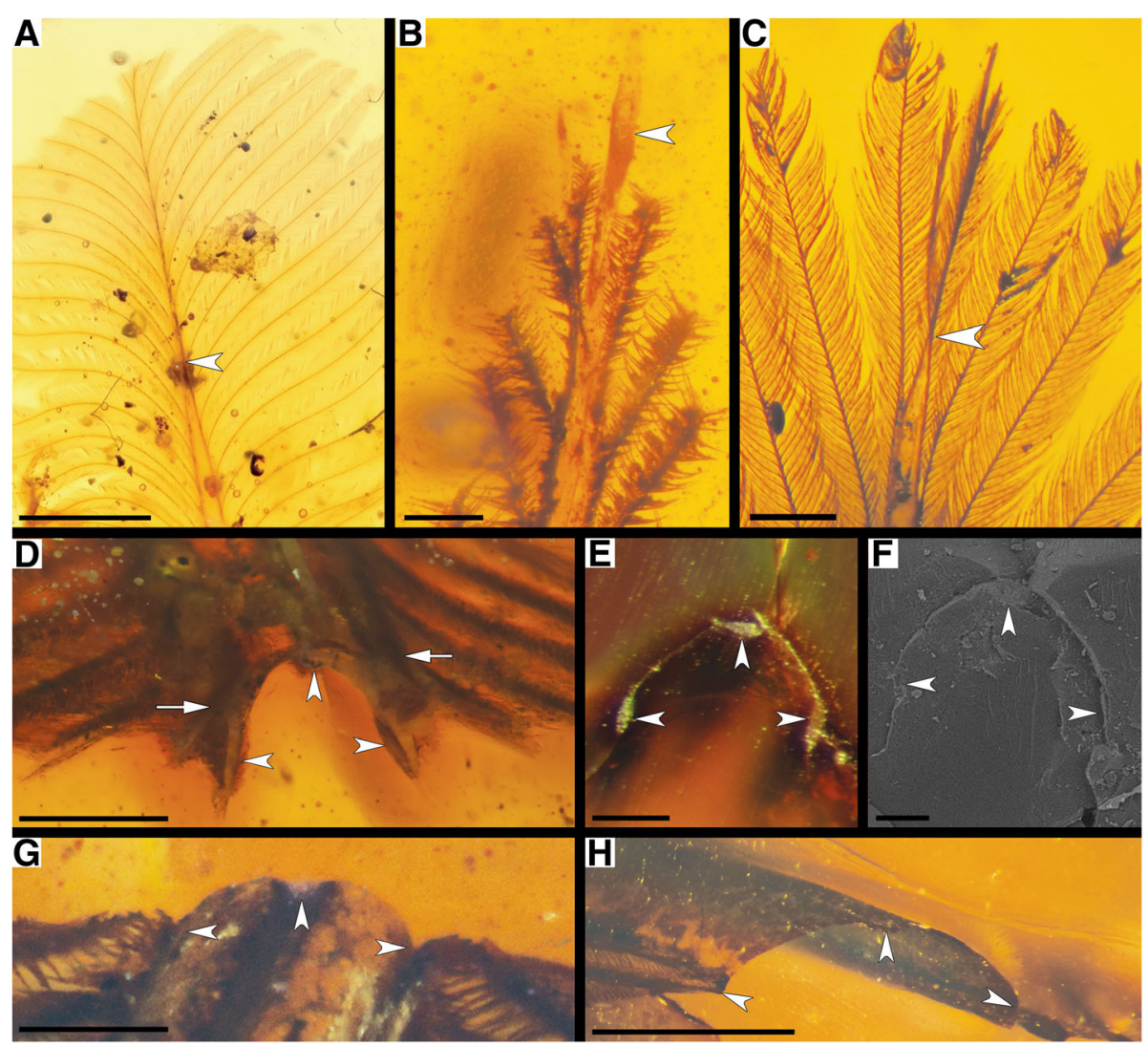

Fig. 2 RDF variations in rachis apices and cross-sectional profiles. a close-up of one of the two feather apices in DIP-V-16186, with tapered rachis leading to just rachidial ridge (arrowhead); $\mathbf{b}$ apex of DIP-V-17109 with broad rachis extending to the end of the vanes (arrowhead); c close-up of the tip of DIP-V-15125, with twisted rachis (arrowhead); $\mathbf{d}$ oblique dorsal cross-sectional view of rachis in DIP-V-16202 exhibiting an expansion on the edges (left and right arrowheads) and thin rachidial ridge (center arrowhead), with barbs attaching to rachis laterally (arrows); e cross-section of the rachis of DIP-V-16208; f SEM image of DIP-V-16207, corresponding to e; $\mathbf{g}$ DIP-V-17109 oblique ventral view of rachis cross-section in one of the two feathers; $\mathbf{h}$ DIP-V-17127 rachis cross-section in oblique lateral view, with rami originating slightly below (left) and exactly on the edge (right), plus thin rachidial ridge. Arrows/arrowheads denote same structures in (d-h). Scale bars $=2 \mathrm{~mm}$ in $(\mathbf{a}) ; 0.25 \mathrm{~mm}$ in $(\mathbf{b}, \mathbf{d}, \mathbf{g}$ and $\mathbf{h}) ; 0.05$ $\mathrm{mm}$ in (c); $0.1 \mathrm{~mm}$ in (e and $\mathbf{f})$

specimens such as DIP-V-17109 exhibit a broad, spatulate rachis tip extending beyond the vanes (Fig. 2b), as observed in compression fossils of confuciusornithiforms, and an enantiornithine (Wang et al. 2014). This exposed rachis tip may be a product of feather wear, or it may be a developmental product. The removal of barbs through wear produces a naked rachis base in the racket plumes of some modern birds (Bleiweiss 1987). However, the barbs that lead up to the exposed rachis tip in the RDFs with this feature show a progressive reduction in length (Fig. 5a) that is more suggestive of a developmental source. One sample displays an unusual rachis that tapers slightly and twists apically, bearing three or four apical barbs (Fig. 2c). These barbs gradually diminish in length and show no sign of truncation.

The rachis structures observed in amber imply a wider range of flexibility than would be expected based on the straight RDFs known from compression fossils (e.g., O'Connor et al. 2012; Wang et al. 2014; Hu et al. 2015).
At the high end of the flexibility spectrum are specimens like DIP-V-17153 and DIP-V-16223 (Fig. 4d, h, i). DIP-V-17153 contains a slender feather with barbs concentrated toward the apex; the rachis is widely opened, appearing thin and extremely flexible throughout its length, but gaining rigidity from its broad, C-shaped profile; the edges of its laminae have rolled inward near the base of the feather (Fig. 4h, i), and are nearly flat apically. At the low end of the flexibility spectrum, some RDFs in amber exhibit a straight and relatively rigid rachis, with a deep, C-shaped cross-section and thickened posterior margins along a lamina that is otherwise less than $50 \mu \mathrm{m}$ thick (e.g., Fig. 2e). It is unclear if these marginal reinforcements are achieved through thickening of the lamina surface, or by the posterior margin of the lamina rolling back on itself: when combined with the rachidial ridge, this creates a series of three somewhat tubular structures that reinforced the C-shaped section of many RDFs (Fig. 6b). Regardless of the depth 
and curvature of the rachis cross-sectional shape, all samples observed had laminae extending from the side of the rachidial ridge that were extremely thin compared to the surroundings of the pith cavity in modern bird feathers (e.g., McKittrick et al. 2012: fig. 14): excluding the rachidial ridge and any thickening near the posterior margin of the laminae, rachis thicknesses in RDFs are generally comparable to those of the adjacent barb rami.

\subsubsection{Barb attachment}

Significant variation also exists in attachments between the lateral laminae of the rachis and the unfused barbs that make up the vanes on each side of the rachis. Some specimens have rami originating from the posterior margins of the laminae (e.g., Fig. 6g), while others have rami situated laterally, removed from the posterior opening in the feather (e.g., Fig. 2d). In the latter specimens, the attachment of barbs high on the side of the rachis leaves a section of lamina that extends below the surface of the vanes. This attachment position varies between specimens, and it can also vary on either side of the same rachis. Barbs in DIP-V-17127 and MCAC-0322 display a relative asymmetry between the two vanes (Fig. 1f, g). On one side, rami originate slightly above the laminar margin, while on the other side, rami are located exactly on the posterior edge, sometimes producing a serrated rachis margin. Combined with the shape of the rachidial ridge, and depth of the cross-sectional profile, variability in branching from the laminae likely influences mechanical properties of the feather, particularly its rigidity.

\subsubsection{Barb branching and barbules}

The dorsal and ventral surface of each RDF can be inferred from the attachment pattern of the barbules to the barbs (Figs. $2 \mathrm{~d}$ and $4 \mathrm{~b}$ ). In the amber specimens the barb rami extend as blade-shaped structures ventral to the barbules, and the rachis opens ventrally to the barbs (Fig. 2d-h). None of the RDFs express strong asymmetry like that observed in modern rectrices. However, some show asymmetric features related to the vanes and the barbules. Several feathers have a short portion of the basal shaft-bearing barbs only on one side further adding to the morphological diversity observed in these tail ornaments (Figs. 3a, 4g, h and 7e, f). DIP-V-17153 (Fig. 4h) bears unpaired barbs along two-thirds of the length preserved below the main vaned feather section, with a notable dissimilarity between barbs and barbules of the two vanes. The left vane is characterized by blade-shaped rami bearing thin, straight barbules, while the right vane has similar proximal barbules, that are thick, straight and rigid (almost acicular); but the distal barbules are thinner, curved, and much longer than the proximal barbules (Fig. 4j). Similarly, some RDFs exhibit a difference between proximal and distal barbules. In these feathers, barbs show a progressive decrease in the relative length of proximal barbules, bearing only distal barbules at the apex (Fig. 6e). In addition to DIP-V-17127 having barbs that attach at different heights on each side of the rachis, there is also a clear asymmetry between barb lengths in each vane (Figs. $2 \mathrm{~h}$ and $8 \mathrm{~g}$ ).

\subsubsection{Pigmentation}

The observable pigmentation in most amber specimens generally produces pale brown overall colors (e.g., Fig. 1a-c). There is some small-scale variability in this coloration, with loosely confined pigmentation spots corresponding to the basal cells in some barbules (Figs. 3d and 8e). Some specimens also appear translucent and would have likely been pale or white in life (Fig. 7c, e). One remarkable specimen (Fig. 4g), has transverse pigmentation banding on the rachis and barbs, producing alternating dark brown and colorless bands. In general, the muted colors preserved in amber RDFs seem to accurately represent the distribution and intensity of pigments from melanosomes, but it is still unclear whether these feathers would have possessed structural colors or additional pigments such as carotenoids (Thomas et al. 2014) that would have created a greater range of colors.

\subsubsection{Occurrence in pairs}

In nine of the specimens studied, a pair of RDFs is preserved adjacent and subparallel to one another (Figs. 5, 6 and 7), and some have been deflected by the same resin flows (e.g., Figs. 5c and 7b). Because of their similar taphonomy, morphology, and microstructure, these feather pairs are each almost certainly from the same individual, most likely representing tail streamers of basal birds. Based on taphonomic features (detailed in Section 3.1.6), many of these pairs appear to have been plucked on impact with resin, as opposed to belonging to corpses. Flow lines indicate that the streamers were dragged through the resin mass, or they are accompanied by numerous non-RDF plumulaceous feathers stuck in a single resin drying line.

\subsubsection{Interactions with resin flows}

Sample observations under ultraviolet light provided additional information about the interaction between the feathers and resin flows. In some samples the flow lines are even visible to the naked eye. In DIP-V-16111, the resin flow lines are clearly observable and suggest that the feather was drawn through a resin flow. Approximately at the mid-length of the feather, the resin flow lines are distorted to form a funnel around the rachis and the barbs (Fig. 3a). In DIP-V-15153, the two feathers are bent apically. The flow lines parallel the specimens, but become perpendicular apically, strongly deflecting the barbs of the feathers (Fig. 5c). DIP-V-17138 also 


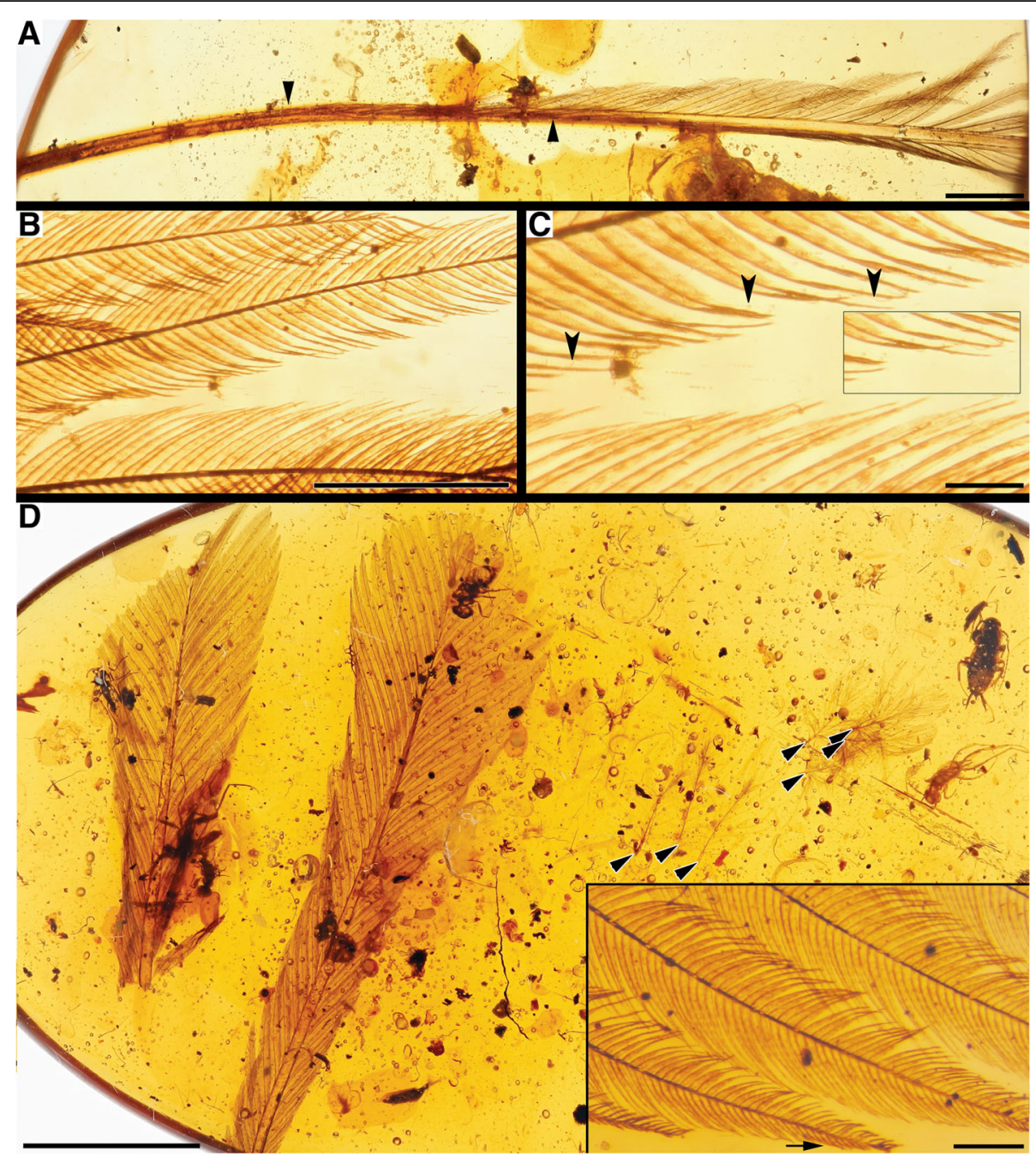

Fig. 3 RDFs with interlocking barbs. a DIP-V-16111 overview with asymmetrical vanes (arrowheads at base of each vane); b DIP-V-16111 barb structure; c DIP-V-16111 barbules with hooklets (inset and arrowheads); d DIP-SY-06231 overview with plumulaceous feathers trapped on drying line (arrowheads), and more detailed view of barb and barbule structure (inset). Scale bars $=2 \mathrm{~mm}$ in (a); $0.5 \mathrm{~mm}$ in (b); $0.1 \mathrm{~mm}$ in (c); $5 \mathrm{~mm}$ in (d); $0.2 \mathrm{~mm}$ in (d) inset

exhibits a series of flow lines paralleling the feather, which could explain the inclination of the vanes (Fig. 8f). These observations suggest that the feathers were highly flexible, and that some feathers were plucked when the animal hit the resin flow rather than being molted feathers or those sourced from corpses. Subparallel RDF alignments (Figs. 5a, d, c, 6d and 7a, c, e) and shared deflections-combined with the presence of only RDFs, or RDFs and a scattering of plumulaceous feathers in pieces of amber without any additional vertebrate inclusions (Figs. 3d and 6a)-point toward impact and adhesion on drying lines in the sample set.

\subsection{Details of individual RDF specimens}

From a functional standpoint, the sample set can be generally grouped into RDFs that exhibit evidence for interlocking barbs (forming more of an aerodynamic surface), and those that show weakly interlocking barbs. Some specimens are observed as pairs, while fragmentary remains can be identified as either diagnostic or putative RDFs based on their observable characteristics.

\subsubsection{RDFs with interlocking barbs}

The feather contained in DIP-V-16111 (Fig. 3a-c), appears slender and slightly curved when observed with the naked eye. The basal-most quarter of the preserved rachis does not bear any barbs along its length, while the second quarter exhibits barbs only on one side. These barbs are sparse, short and adpressed. The rest of the rachis bears pennaceous barbs with blade-shaped rami attached to the posterior edges of the laminae with a divergence angle of $\sim 20$ degrees. Barbules stem from 


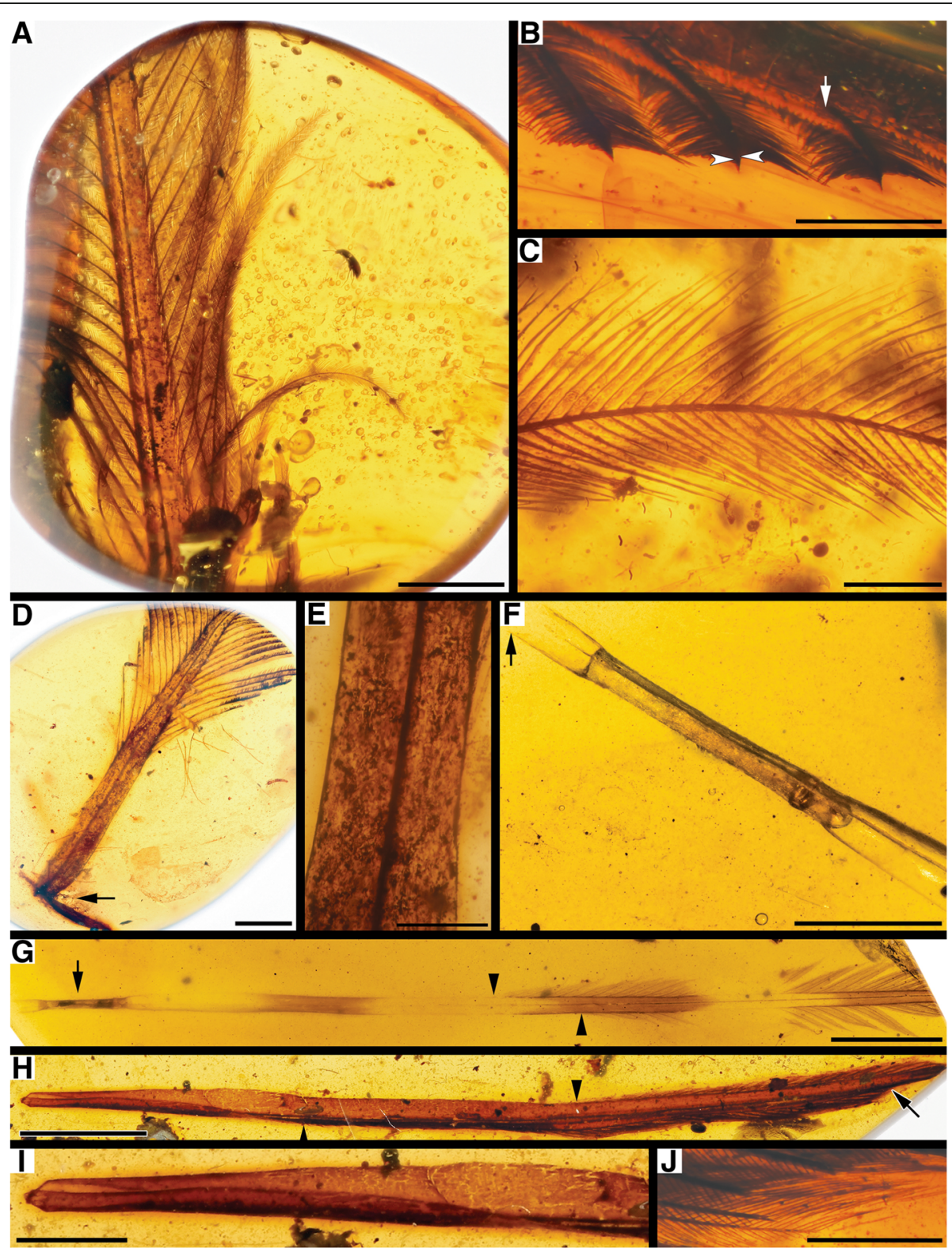

Fig. 4 RDFs with weakly interlocking barbs. a DIP-V-16202 overview; b cross-section of the barbs of DIP-V-16202, arrowheads indicate barbule origination points, arrow indicates barb origination on posterior margin of rachis; c DIP-V-16202 barb, with pigment banding in barbules; d DIP-V16223 overview, arrow indicates bending point in rachis; e detail of rachis and rachidial ridge in DIP-V-16223; $\mathbf{f}$ base of rachis for DIP-V-17180 (overview in $\mathbf{g}$ ), arrow indicates breach of rachis base on polished surface of amber piece; $\mathbf{g}$ DIP-V-17180 overview, arrow indicates basal constriction detailed in F, arrowheads mark asymmetrical bases of feather vanes; $\mathbf{h}$ DIP-V-17153 overview, arrowheads mark asymmetrical bases of feather vanes, arrow indicates exposed barbs featured in $\mathbf{j}$; i detail of inwardly rolled rachis base on DIP-V-17153; $\mathbf{j}$ cross-section of barbs of DIP-V17153 showing elongate distal barbules. Scale bars $=2 \mathrm{~mm}$ in (a, $\mathbf{d}, \mathbf{f}$ and $\mathbf{i}) ; 0.5 \mathrm{~mm}$ in (b); $0.2 \mathrm{~mm}$ in (c and $\mathbf{j}) ; 1 \mathrm{~mm}$ in $(\mathbf{f}) ; 5 \mathrm{~mm}$ in $(\mathbf{g}$ and $\mathbf{h})$

barbs, also from the laminae in all regions of the feather that bear barbs. These barbules appear analogous to the rachidial barbules that occur in contour feathers of modern birds (Lucas and Stettenheim 1972). In DIP-V-16111 the barbules are blade-shaped, with proximal barbules tapering to a narrow apex, whereas distal barbules exhibit a thick pennulum bearing hooklets (Fig. 3c). In distal regions of the barbs, proximal barbule lengths decrease, and they disappear at the extremity, leaving barbules on only the distal side of the ramus. Pigmentation within the barbules is diffuse and interrupted by barbule subdivisions (Fig. 3c). Overall, the apparent preserved color of the feather is pale brown, with darker rami and rachidial ridge, and pale brown laminae.

DIP-SY-06231 (Figs. If and 3d) contains two types of feathers probably belonging to the same animal - two ornamental feathers are preserved alongside numerous 


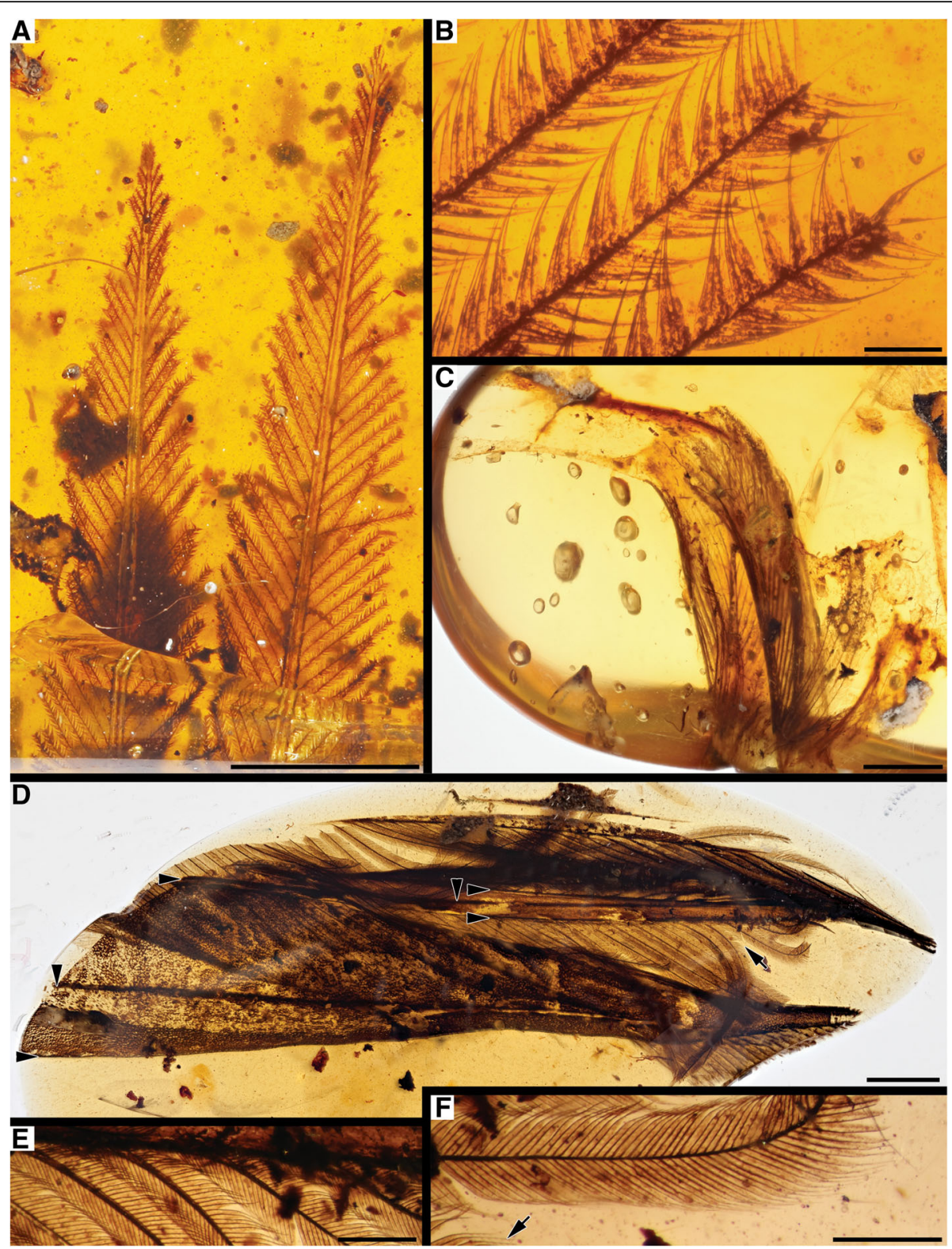

Fig. 5 Paired RDFs. a DIP-V-17109 overview; b barbs of DIP-V-17109 with clumped barbules and blunt barb apices; c DIP-V-15153 overview, with feather apices deflected dorsally (to left) by resin flows, but rachis unaffected; d RSKM_P3306.58 overview, horizontal arrowheads mark rachis lateral margins, vertical arrowheads mark rachidial ridges, arrow denotes area for detailed images in $\mathbf{e}$ and $\mathbf{f}$; e detail of barb bases and lateral attachment to the rachis in RSKM_P3306.58; $\mathbf{f}$ detail of barbules in RSKM_P3306.58, arrow highlights hooklets on distal barbules. Scale bars $=5$ $\mathrm{mm}$ in (a); $0.2 \mathrm{~mm}$ in (b); $2 \mathrm{~mm}$ in (c and $\mathbf{d}) ; 0.5 \mathrm{~mm}$ in (e and $\mathbf{f}$ )

plumulaceous feathers (Fig. 3d). The RDFs differ in general morphology from DIP-V-16111 (described above) but share some key features. Similarities include: barb rami that are blade-shaped and branching from the posterior edges of the laminae (average divergence angle of 23 degrees); exhibiting rachidial barbules and asymmetry between proximal and distal barbules that is reduced apically (Fig. 3d); and having barbules that are similar in morphology and bear hooklets. However, in DIP-SY-06231, the rachis is progressively tapering, with the distal sections of the exposed rachidial ridge very similar in morphology and size to the surrounding barb rami. The same apical taper is observed in DIP-V-15153 and DIP-V-16186. In DIP-SY-06231, the rachidial ridge is barely visible as a simple brown line. Pigmented areas within the RDFs in this sample give the specimens an overall medium brown appearance. At a finer scale, diffuse pigmentation within the barbules is interrupted by circular spots that appear to correspond to the center of each barbule internode (Fig. 3d). Pigmentation 


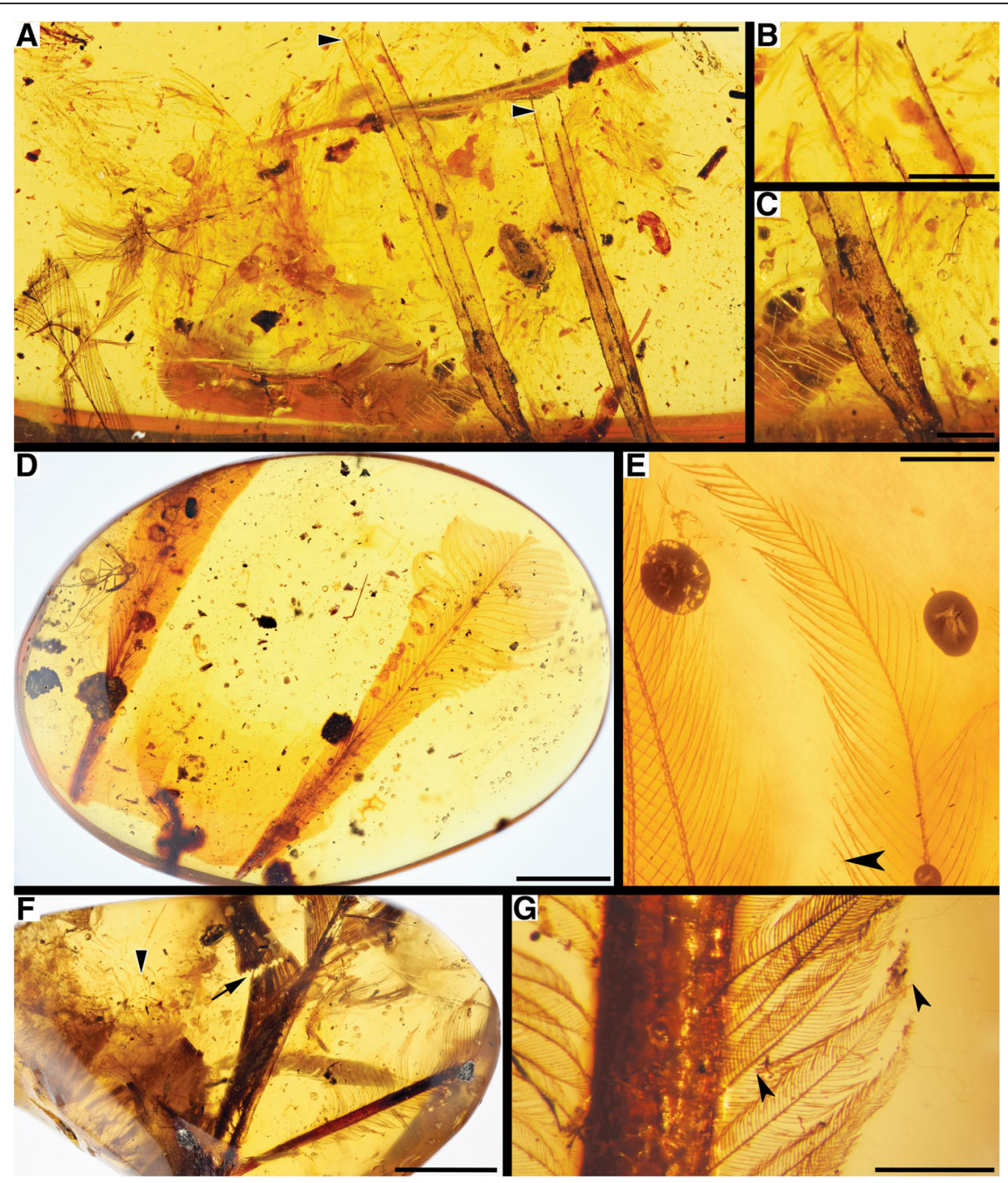

Fig. 6 Paired RDFs. a DIP-V-16164 partial overview, with RDF rachises indicated by arrowheads; b oblique section through one rachis in DIP-V16164; c distorted rachis near base of DIP-V-16164; d DIP-V-16186 overview; e barbs of DIP-V-16186, arrowhead indicating hooklets; f DIP-V-17137 overview, arrow indicating taphonomic tear in vane, arrowhead indicating region with numerous plumulaceous feathers; $\mathbf{g}$ details of rachis, barbs, and barbules in DIP-V-17137 RDF (on right side of $\mathbf{f}$ ), with bristle-like feather floating in amber between arrowheads. Scale bars $=5 \mathrm{~mm}$ in $(\mathbf{a}, \mathbf{d}$ and $\mathbf{f}) ; 1 \mathrm{~mm}$ in (b and $\mathbf{c}) ; 0.2 \mathrm{~mm}$ in (e); $0.5 \mathrm{~mm}$ in $(\mathbf{g})$

becomes more concentrated toward the apex of each barbule and is significantly darker within the barb rami. The plumulaceous feathers found as syninclusions in DIP-SY-06231 are preserved all the way down to the calamus, preserving a hollow, pith-filled rachis. The bases of the feathers are plumulaceous, while the tips of some feathers are pennaceous. These feathers appear to lack pigmentation as preserved, suggesting a pale or white appearance in life.

\subsubsection{RDFs with weak barb interlocking}

In DIP-V-16202 (Figs. 2d and 4a-c) the pronounced rachidial ridge is slightly displaced from the rachis midline (Fig. 4a). The angle between the rami and the laminae is approximately 30 degrees, and barbules are present between rami. Barb rami are blade-shaped, originating laterally from the side of the laminae. Both proximal and distal barbules are straight, narrow, and blade-like, with no visible differentiation into a pennulum bearing hooklets in the distal barbules. Diffuse pigmentation is preserved in the base of the barbules, and its minor mottling hints at barbule subdivisions.

DIP-V-16208 (Figs. 1b and 2e) shares many structural features with DIP-V-16202. However, in the former specimen, the rachidial ridge is less pronounced, and appears to be absent under transmitted light (Fig. 1b) due to a thin veneer of pyrite along the inner surface of the rachis. A rachis cross-section shows a thin rachidial 


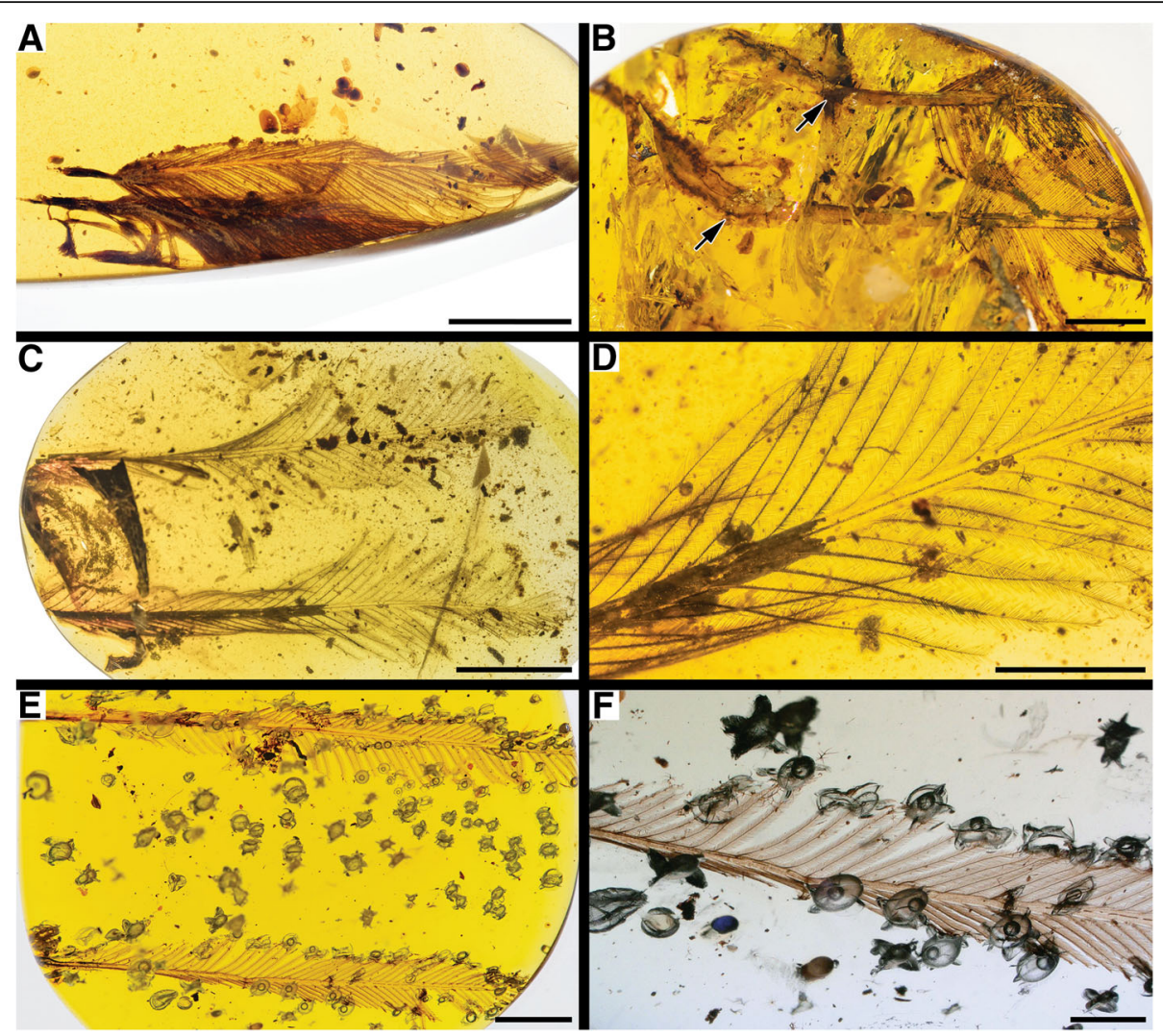

Fig. 7 Paired RDFs. a DIP-V-16105 overview; b DIP-V-17177 overview of paired, bent feathers, with arrows marking ventral deflection point; c DIP-V-17194 overview; d detail of DIP-V-17194 barbs; e MCAC-0322 overview; f detail of vane bases in MCAC-0322 (lower feather in e). Scale bars $=5 \mathrm{~mm}$ in (a-c and $\mathbf{e}) ; 2 \mathrm{~mm}$ in (d and $\mathbf{f}$ )

ridge, as well as a tubular thickening at the posterior margins of the laminae, slightly ventral to the barb origination points (Fig. 2e). Barb and barbule structure in this specimen are reduced and poorly interlocking, but the high density of blade-like barbules combine to produce relatively closed and complete vanes. Visible pigmentation gives an overall medium brown coloration that is overprinted distally and in the rachis by opaque deposits of pyrite.

The feather in DIP-V-16223 (Fig. 4d, e) has a proportionally wide (1.14 mm basally) and deep rachis (Fig. 4e). The rachidial ridge is unusual, with a prominent blade-shape. The rami branching points are located laterally on the laminae, and barb and barbule morphology are similar to those found in the other weakly interlocking RDFs. Traces of pigmentation give a pale brown apparent coloration to the feather, overprinted by deposits of pyrite on the rachis and distal half of the barbs. The rachis is folded ventrally 90 degrees at the base, where it has been redirected by resin flows. Between this deflection and the base of the feather's vanes, the lateral margin of the rachis is torn longitudinally and curled adapically, revealing that the lamina is thinner than a barb ramus.
DIP-V-17180 (Fig. 4f, g) is elongate, with narrow and asymmetrical vanes apically, and an extensive rachis without barbs basally. The feather apex is largely preserved, but both the feather apex and base breach the amber surface: it is unclear how much of its length is missing. Four broad color bands extend across the feather's length, with the bands toward the apex of the feather forming a subtle chevron pattern (Fig. 4g). The pigments that produce the apparent medium brown color bands are diffuse within the rachis and barbs, and slightly concentrated within the rachidial ridge. Barbs appear to originate from the ventral margin of the rachis on both sides, and end in acute apices. Barbs are widely separated, with limited potential for overlap or interlocking to form a closed vane. The barbules are blade-shaped. The basal-most pigmented area of the rachis has drawn inward, forming a complete ring (Fig. 4f). There is an air bubble trapped within this region of the rachis, so it is unclear if the constriction is related to high flexibility, partial decay, or if the constricted region may represent the follicle insertion point for the feather. Unfortunately, the feather is cross-cut by the polished surface of the amber basally, making it impossible to determine if the absolute base is preserved. 


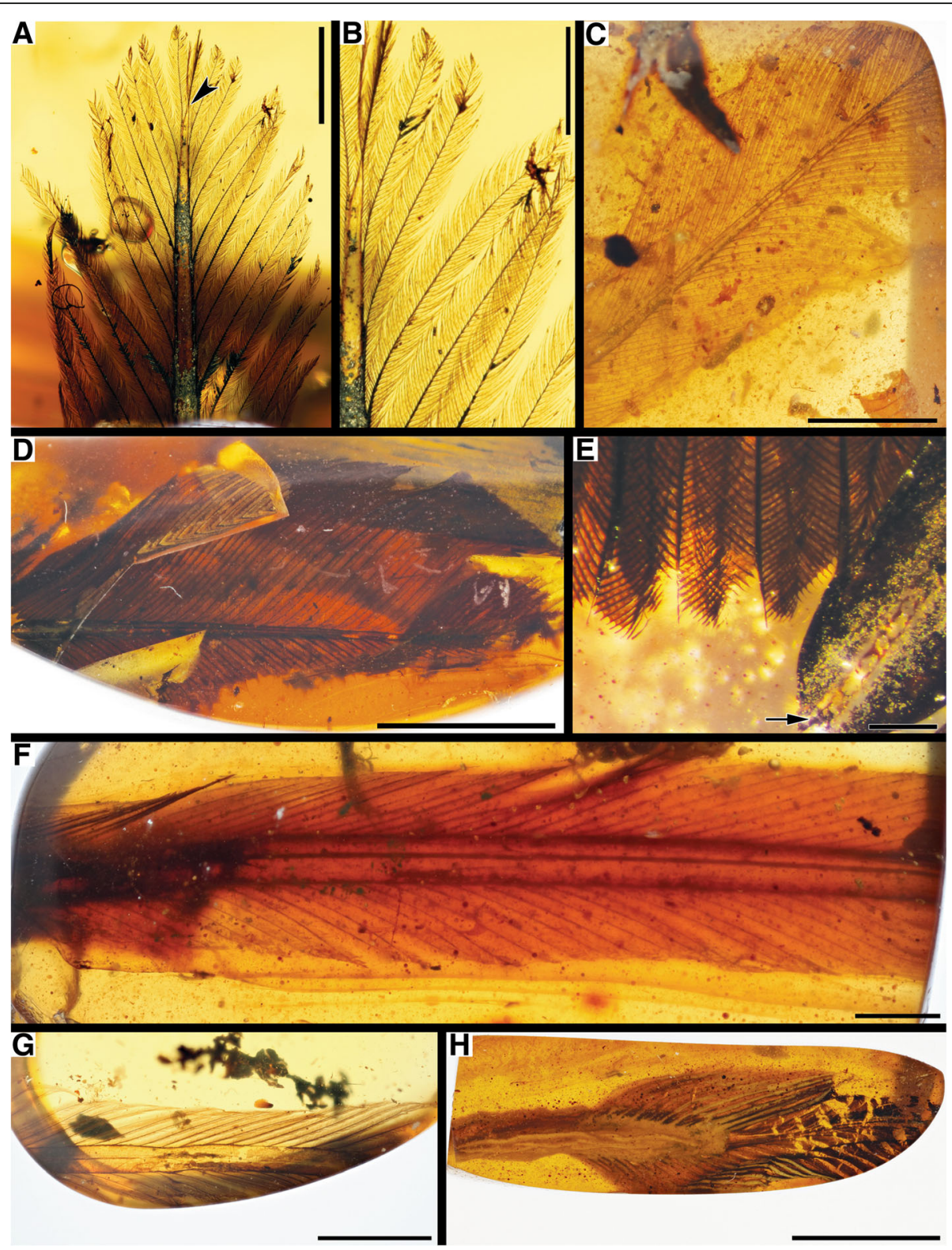

Fig. 8 Diagnostic RDF fragments. a DIP-V-15125 overview, arrowhead marks twist in rachis; b details of barbs and barbules in DIP-V-15125; c DIPV-16115 overview; d DIP-V-17121 overview; e detail of DIP-V-17121 rachis and barbs, where they are cross-cut by polished surface of amber (left margin of $\mathbf{d}$ ), arrow indicates rachidial ridge; $\mathbf{f}$ DIP-V-17138 overview; $\mathbf{g}$ DIP-V-17127 feather section; $\mathbf{h}$ DIP-V-16207 overview. Scale bars $=1 \mathrm{~mm}$ in (a); $0.5 \mathrm{~mm}$ in (b); $5 \mathrm{~mm}$ in (c, $\mathbf{d}$ and $\mathbf{g}) ; 0.2 \mathrm{~mm}$ in (e); $2 \mathrm{~mm}$ in (f and $\mathbf{h}$ )

DIP-V-17153 (Fig. 4h-j) contains a slender feather with few barbs inserted on the posterior edges of the laminae (Fig. 4h). As in DIP-V-16233, the rachis in DIP-V-17153 is widely open, but in the latter specimen it seems to be very thin and extremely flexible-near the base of the feather, on both sides of the rachidial ridge, the edges of the laminae are rolled inward, toward the rachidial ridge (Fig. 4i). The apex of the rachis is almost flat. Along the laminae, barbs are borne only on one side across the middle one-third of the feather's preserved length, and the barbs and barbules exhibit a different morphology depending on the vane observed. The left vane (in ventral view) is formed by blade-shaped rami bearing thin, relatively straight barbules, while the right vane has rami that are also blade-shaped but appear much thicker. The proximal barbules are especially thick, straight and rigid, appearing acicular, while distal barbules are thin, curved, and several times longer than the proximal ones (Fig. 4j). There is no evidence of the presence of hooklets on any of the visible barbules. It is unclear if the inwardly rolled base of DIP-V-17153 has been torn free from the remainder of the rachis, or if it might 
represent the insertion point into the follicle (Fig. 4i). The rachidial ridge becomes less deep, and the laminae appear to taper inward near the base of the rachis, but they also present a somewhat jagged edge basally. If this is the true base of the feather, it is not surrounded by a calamus despite being fully encapsulated in resin. This is unlike the bases of plumulaceous feathers that are found alongside RDFs in specimens such as DIP-SY-06231 (Fig. 3d).

\subsubsection{Paired RDFs}

In DIP-V-17109 (Figs. 1c, 2b, g and 5a, b), the rachis is partially obscured by pyrite deposits, but it is very broad, and ends in a blunt tip that extends to the edge of the feather vanes (Figs. 2b and 5a). This character has been reported in confuciusornithiforms as well as in an enantiornithine (O'Connor et al. 2012) compression fossils. Given their morphology, and the other findings from Burmese amber (Xing et al. 2016a, b, 2017), these feathers probably originated from the tail of an enantiornithine. The rachidial ridge is twice as thick as the rami within the feather (Fig. 2g). The rami are inserted relatively high on the sides of the laminae, far removed from the posterior margin, and diverging with an angle of about 30 degrees. Barbules possess a large base and are locally joined to form clusters of 3-5 barbules (Fig. 5b). It is not entirely clear whether this clumping is part of the original structure of the feather, or taphonomic in origin. Nonetheless, the same clumping feature is observed in DIP-V-16113, along with similar blunt barb apices. This points toward a structural as opposed to taphonomic explanation. Regions of the feather in DIP-V-17109 that are not obscured by pyrite deposition appear to lack pigmentation, suggesting a pale or white feather in life.

DIP-V-15153 (Fig. 5c) contains two feathers that are truncated basally. The amber surface provides a lateral view of the feathers side by side and with the tips deflected dorsally (towards the right in Fig. 5c) by interactions with a resin flow. The rachis tapers distally to just the rachidial ridge, and rami origination points are located on the very posterior edges of the laminae. Long barbs with blunt apices contain reduced, slightly curved barbules that continue as rachidial barbules. Apparent pale brown coloration is generated through diffuse pigmentation in the barbules, barb rami, and rachis.

RSKM_P3306.58 (Fig. 5d-f) contains two closely adpressed RDFs with different rachis morphologies. It is unclear whether these specimens represent two distinct morphotypes, or if they are a matching pair that have simply been sectioned at different points along their lengths. The RDF with an exceptionally broad rachis has a barbless base that exceeds $5 \mathrm{~mm}$ in width (lower specimen in Fig. 5d), but it tapers apically to less than $1 \mathrm{~mm}$ in width. It also bears barbs apically that are similar to those found on the RDF with a narrower rachis (upper specimen in Fig. 5d). The narrower specimen is vaned throughout its preserved length. Both RDFs have a prominent rachidial ridge that appears slightly concave on the dorsal surface of the rachis, and both RDFs have barbs that attach to the posterior margin of the rachis on one side (Fig. 5e), but the lateral surface on the other side. Barb rami are deeply blade-shaped. Proximal barbules are blade shaped with a weak apical taper and curvature and a divergence angle of approximately $38^{\circ}$, while distal barbules have broad, blade-shaped bases that diverge at approximately $50^{\circ}$, followed by a distinct pennulum that curves apically and bears hooklets (Fig. $5 \mathrm{f}$ ). Preserved coloration appears to indicate a dark brown rachis and rami, with medium-brown pigmentation in the barbules that is diffuse but provides weak indications for seven nodes within the basal plate of each barbule.

DIP-V-16164 (Fig. 6a-c) preserves two adjacent and subparallel rachis bases without any barbs. One of them exhibits a distortion basally: the laminae deflect to create regions of the rachis that are broad and narrow, showing some flexibility (Fig. 6c). The amber also contains a contour feather and more than 20 plumulaceous feathers, many of which have a similar orientation to one another but do not attach to a sheet of skin (right side of Fig. 6a). These feathers appear to be trapped along a different plane, but under UV light, all feather inclusions are clearly part of the same resin flow. This association seems to support a scenario in which an animal struck the resin flow and left behind a mixture of predominantly down feathers and a pair of RDFs consistent with tail feathers.

DIP-V-16186 (Figs. 1a and 6d, e) contains two feathers, one of which preserves the rachis tapering suddenly to just the rachidial ridge (Fig. 1a). Thick rami insert slightly above the posterior edges of the laminae. The angle between the rami and the rachis is about 20 degrees. The barbules bear hooklets and a diffuse, weak pigmentation, suggesting a pale original feather color, and weak attachment between the barbs (Fig. 6e).

DIP-V-17137 contains two types of feathers (Fig. 6f, g): two overlapping RDF fragments, and numerous plumulaceous feathers preserved down to the calami (Fig. 6f). Some plumulaceous feathers exhibit a pennaceous tip (suggesting contour feathers), but detailed observation is complicated by abundant bubbles and milky amber in this region. The largest piece of RDF exhibits strong taphonomic distortion: the vanes, which are composed of barbs that are straight and interlocking, are folded and torn. The rami have a divergence angle of approximately 15 degrees and are inserted relatively low on the sides of the laminae. The barbules have a short and weakly developed pennulum-bearing hooklets, and a base with a faint pigmentation concentrated near the apex of the basal cell 
(Fig. 6g). The second fragment of RDF exhibits rami that are less thick. The barbs are folded and more open in their arrangement, with some barbs bound by spider silk. Although this amber piece contains a pair of RDFs, and may also be related to an impact event, the feathers are not as uniform in morphology and subparallel in orientation as the other pairs. These feathers may have entered the resin due to an impact, but they cannot be as confidently interpreted as paired tail feathers. Next to the right vane (highlighted in Fig. 6g), is a structure that looks like a hollow spike. The morphology and the size are compatible with the interpretation of a filament feather, such as those observed in other enantiornithines found in Burmese amber (Xing et al. 2017). Some of the plumulaceous feathers found as syninclusions within this amber piece have faint pigmentation, with nodes and internodes barely visible.

DIP-V-16105 (Fig. 7a) contains two adjacent feathers that underwent a strong distortion: the rachises and the rami are taphonomically flattened. Due to this flattening, details of the rachis are unclear, and the rachidial ridge appears to be absent. The rami have thick bases that insert deeply and broadly into the margins of the laminae. The barbs are highly asymmetrical (with one vane more than four times as wide as the other). Proximal barbules are blade-like and gently curved, while distal barbules have a blade-like base followed by a weakly developed pennulum that angles adapically from the base. Given the combined differences between DIP-V-16105 and the rest of the sample set, these feathers are less confidently placed in the RDF category.

Paired RDFs within DIP-V-17177 (Fig. 7b) are obscured by numerous fractures within the surrounding amber, but many of their details remain clear. The two feathers are subparallel to one another, including a deflection of roughly 135 degrees that occurs within the basal part of their rachises. Rachis details basal to this deflection point are less clear, but they appear to have flared laterally, likely because their $\mathrm{C}$-shaped cross-sections were spread open by resin flows. Within the vaned portion of each feather, the rachises are preserved with greater translucency, while basal details are masked by milky amber. Rachidial ridges are prominent, and barbs branch from the lateral surfaces of each lamina. Barbs within one vane (uppermost in Fig. 7b) appear to branch from the rachis at a lower angle than in the other vanes, but this may be influenced by resin flows. The apex of each vane is not preserved. The loosely arranged barbs have blade-shaped rami and taper gradually along their lengths. Barbules are reduced and blade-shaped with no visible traces of hooklets or segmentation. Pigmentation appears weak and diffuse within the barbules, and slightly darker within the barb rami and rachis, but the thick and fractured surrounding amber precludes study under high magnifications.
DIP-V-17194 (Fig. 7c, d) contains the vaned apices of two subparallel RDFs partially veiled by pyrite deposits. The basal barbs within each vane are curled ventrally, likely from being drawn through the resin or having resin flow around the feathers (a couple of broken barb sections between the two feathers are also displaced ventrally). Pigmentation within the barbs and rachis is faint or absent, likely indicating a pale or white feather in life. The rachidial ridge is tubular and approximately $40 \mu \mathrm{m}$ in diameter, with a mottled appearance (Fig. $7 \mathrm{~d}$ ) - it is not entirely clear whether this mottling is the result of pigmentation or of spongy tissue within the rachidial ridge. The $\mathrm{C}$-shaped cross-section of the rachis is broader than it is deep, and barbs attach to its posterior margins on both sides to form loose vanes. The rachis does not taper strongly, extending slightly past the apical barbs as a spatulate tip, and the rachidial ridge becomes faint apically. The barbs have blunt tips (barbules remain long near the apex, extending well beyond the tip of the barb ramus). Barbules have a reduced, blade-shaped morphology, and there is little differentiation between proximal and distal barbules. Proximal barbules diverge at a slightly lower angle than distal barbules, but these angles are inconsistent because all barbules are clumped into groups of two or three, albeit less dramatically clumped than in DIP-V-17109 (Fig. 5b).

MCAC-0322 (Figs. 1g and 4e, f) contains paired RDFs surrounded by bubbles that have developed expansion cracks, but the surrounding amber is exceptionally clear. Reduced pigmentation in the feathers permits detailed study of their rachis structure (Fig. 1g). Each feather has most of its vaned section preserved, along with part of the barbless rachis. In general, the outer margin of each feather has shorter barbs with more robust rami and less divergence than the inner margin, and an asymmetric absence of barbs exists within the basal one-third of the outer vane (Fig. 7f). Many of the barbs within these feathers are widely spaced and cannot connect. The rachis appears to remain broad all the way to the apex of each feather, although the apices are not fully preserved. The rachidial ridge is faint and sporadic. Barbs attach laterally along the inner edge of each feather and attach to the posterior margin of the rachis along the outer edge of each feather. This variation in branching can be seen in multiple specimens, but is most clearly observed in the thin strip of lamina present ventral to the barb bases, as well as the continuation of rachidial barbules along the lamina's lateral surface (i.e., 'right' rachis margin in Fig. 1g) - this branching pattern contrasts with the posterior margin originations that leave a notched appearance and barbules along the posterior margin (i.e., 'left' rachis margin in Fig. 1g). MCAC-0322 displays blunt barb tips, because barbule length does not diminish rapidly toward the apex of each barb. The barbules are blade-shaped and simple, lacking hooklets. 
Weak, diffuse pigmentation is present within the barbules, and slightly darker pigmentation is present within the barb rami and rachidial ridge. These feathers would likely have been pale in life, and their structure and asymmetry strongly suggest that they are tail paired streamers, likely from an enantiornithine.

One additional pair of RDFs was encountered: DIP-SY-06231. This specimen is described in Section 3.2.1 because of its interlocking barbs.

\subsubsection{Diagnostic RDF fragments}

Sample DIP-V-15125 (Figs. 2c and 8a, b) yielded a small fragment (length: $4.1 \mathrm{~mm}$ ) of a feather that is partially veiled by a film of pyrite on parts of the rachis and barbs (Fig. 8a). The rachis tapers strongly and presents an unusual twisted shape with 3 or 4 barbs attached at the extremity apically (Fig. 2c). No rachidial ridge is visible basal to this twisted apex. The barbs share the same blunt ends observed in sample DIP-V-17109, but the barb terminations in DIP-V-15125 are less abrupt. The barbules display a preserved pigmentation with spots of reduced pigment density outlining at least five basal cells, and hooklets are present (Fig. 8b).

DIP-V-16115 (Fig. 8c) is very rich in particulate inclusions, trichomes, organic material and insects, suggesting an origin on the forest floor (Perrichot 2004). One portion of a feather (lacking the tip and basal parts) was found in this sample, and it has a tapering rachis. The barbs are very long and branch out from the posterior edges of the laminae. The rami are slightly inclined toward the rachidial ridge and bear relatively straight proximal barbules whereas the distal barbules are more curved. The sample is too thick to fully observe pigment distribution, but the apparent color for the entire feather is pale brown.

DIP-V-17121 (Fig. 8d, e) contains a large botanical inclusion that obscures much of a feather with rachis width decreasing gradually toward the apex. The angle between the laminae and the rami is about 35 degrees. The left vane (in dorsal view) is formed by very long barbs, which are much more elongate than those forming the right vane, even after accounting for truncation at the edge of the amber piece (Fig. 8d). There is a high density of barbules on all feather sections, and the terminal section of each barb bears proximal barbules decreasing in length until they disappear just at the tip. The pennulum that is present in the distal barbules is about one-third or less of the barbule's total length. Well-visible pigmentation produces a dark brown apparent coloration to the feather and, at a finer scale, pigmentation is concentrated in discreet areas within the barbules (Fig. 8e).

The fragment of oxidized feather in DIP-V-17138 (Figs. 1e and $8 \mathrm{f}$ ) preserves part of the mid-length of a
RDF with a particularly deep rachis and clearly visible rachidial ridge. The vanes are oriented toward the midline of the feather and the rami origination points are located on the posterior edges of the laminae. Thick barbs are present, and these contain simple, blade-shaped (reduced) barbules. Oxidation of the amber imparts a reddish coloration, but aside from this taphonomic feature, the feather appears to preserve a pale brown overall color.

DIP-V-17127 (Figs. 2h and 8g) contains a fragment of feather that underwent distortion. The thin rachidial ridge is barely preserved apically and appears to have been offset to the right (in ventral view) compared to the basal portion. Barbs branch from different locations on either side of the main shaft: slightly below the posterior edge of the lamina and exactly on the edge (Fig. 2h). Rami are blade-shaped; and the apical portion of the barbs possesses proximal barbules decreasing in length to become shorter than distal ones, progressively disappearing at the tip. Barbules are present on the laminae as well as the barbs. Overall, the specimen is preserved with an apparent brown pigmentation.

The feather in DIP-V-16207 (Figs. 2f and 8h) is poorly preserved, partially fragmented, degraded, and hidden by milky amber, making observations difficult. However, the characteristic deep $\mathrm{C}$-shaped rachis with rachidial ridge is observable. Dark brown pigmentation is present throughout the barbs and rachis of this sample. A cross-section of the rachis provided material for SEM imaging (Fig. 2f).

DIP-V-16113 (Fig. 9a) contains the tip of a feather. The study of the specimen is strongly hindered by numerous syninclusions, bubbles, and resin flows. The rachis is strongly curved apically and bears flexible barbs with blunt apices similar to DIP-V-17109. Like DIP-V-17109, the barbules are also locally aggregated to form clumps.

The feather fragment in DIP-V-17232 (Fig. 9b) encompasses part of the vaned section of a RDF. Its broad rachis is deeply concave in cross-section, and it bears a prominent rachidial ridge. The dark, mottled appearance of the rachis, and the darker rachidial ridge appear to reflect original pigment distribution, as opposed to being taphonomic features. Barbs within DIP-V-17232 have blade-shaped rami that attach to the lateral surface of the rachis to form laterally directed vanes. Barbules have a pale brown apparent color because of diffuse pigmentation, with faint areas of reduced pigmentation along the proximal margin of each internode highlighting segmentation within the barbules. Both proximal and distal barbules have a reduced, blade-shaped morphology, and faint traces of hooklets are visible on the distal barbules. Proximal barbules do not continue to the apex of each barb, leaving an acute tip with a short section bearing only distal barbules. 


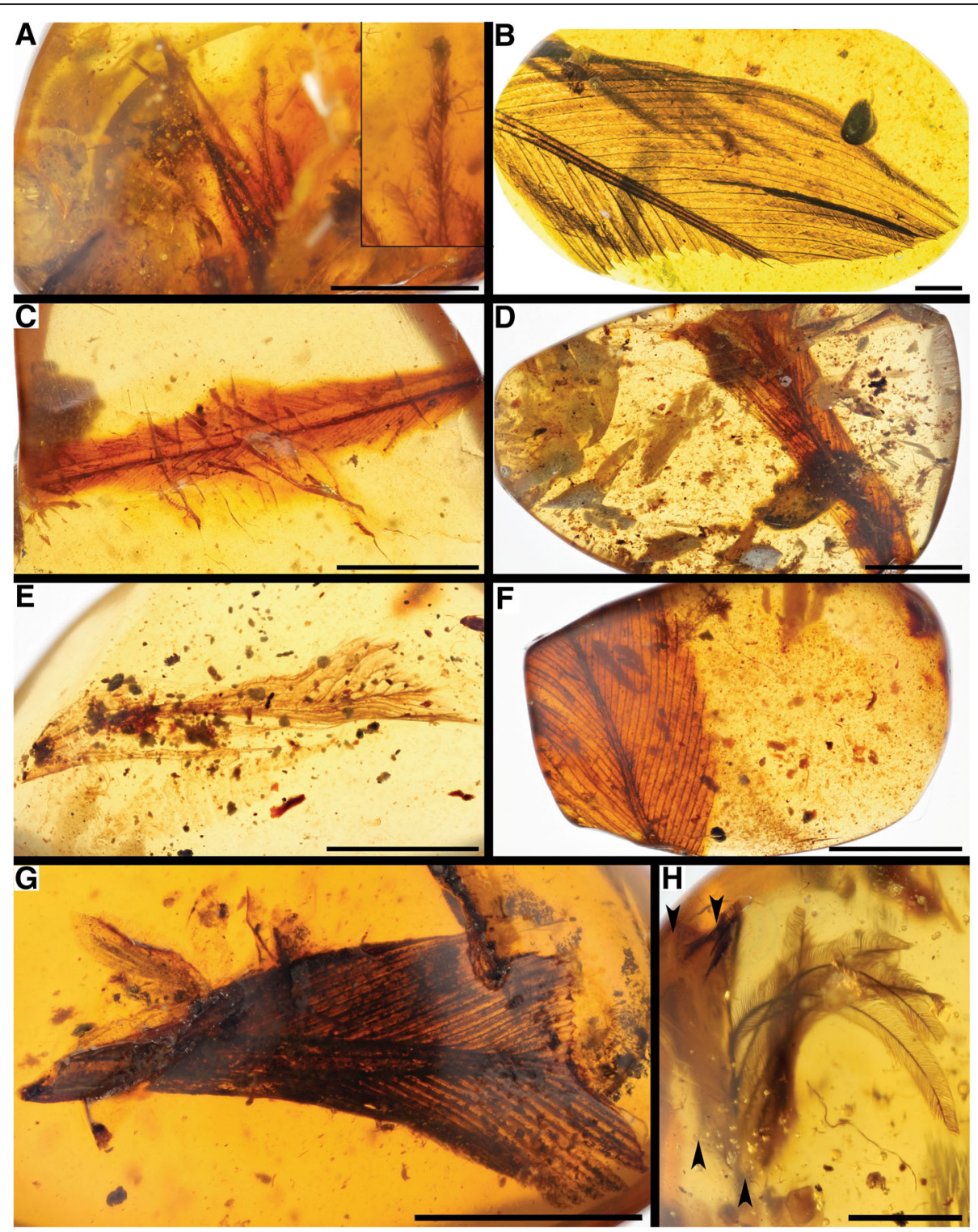

Fig. 9 Diagnostic and putative RDF fragments. a DIP-V-16113 overview and close-up of the tip of the feather (inset); b DIP-V-17232 overview with prominent rachidial ridge and deep C-shaped rachis; c DIP-V-15130 overview; d DIP-V-15137 overview; e DIP-V-15141 overview; f DIP-V-15142 overview; $\mathbf{g}$ DIP-V-15159 overview; h DIP-V-16178 overview, arrowheads mark lateral margins of rachis at both ends. Scale bars $=2 \mathrm{~mm}$ in $(\mathbf{a}$ and h); $1 \mathrm{~mm}$ in (b); $5 \mathrm{~mm}$ in (c-g)

\subsubsection{Putative RDF fragments}

Additional samples have been identified as potential RDFs, but limited preservation does not allow confident identifications. DIP-V-15130 (Fig. 9c) contains an oxidized fragment of feather with numerous transverse cracks and abundant pyrite. Apparent brown reddish coloration in this sample is due to the taphonomic oxidation. A tapering, deep, C-shaped rachis with a rachidial ridge allows placement among the RDFs with some confidence. Short barbs within this feather appear to branch from slightly below the posterior margins of the laminae. DIP-V-15137 (Fig. 9d) contains a fragment of feather trapped within a piece of amber with abundant syninclusions and organic matter, as well as clumps of trichomes from plants. The poorly preserved feather in DIP-V-15141 (Fig. 9e) is partially fragmented, with a strong distortion. Rami (particularly in one vane) are strongly coiled as are some barbules at the tip of the feather. Basally, at the edge of the piece of amber, a portion of a C-shaped rachis with a faint ridge is observable, suggesting an RDF identification. DIP-V-15142 (Fig. 9f) contains a fragment of feather with a rachis that is slightly tapering, and a blade-like rachidial ridge. Barbs branch laterally, low on the sides of the rachis. Deposits 
of pyrite are concentrated on the rami and the rachis. DIP-V-15159 (Fig. 9g) contains a feather that is sectioned basally and apically at the surface of the amber piece. Abundant deposits of pyrite complicate the study of the specimen. The rachis tapers apically, and the vanes are folded toward the anterior mid-line. DIP-V-16178 (Fig. 9h) contains a fragment of feather at the periphery: the rachis was partially polished away. A few long barbs are curved and oriented toward the inner part of the sample. In the apical portion of the barbs, the proximal barbules decrease in length and disappear at the tip. A loosely confined brown pigmentation is preserved, with pale spots outlining the basal cells of the barbules, and hooklets are present.

\section{Discussion}

\subsection{Function}

The differences observed in RDF cross-sectional morphology would have produced a range of flexural stiffness without differences in the material properties of keratin (Bonser and Purslow 1995). Some of the specimens have bent or folded because of interactions with resin flows (Figs. 4d, 5c and 7b), indicating that the open rachis may have bent more easily than the closed rachis found in modern racket plumes (Bleiweiss 1987) or normal flight feathers (Lucas and Stettenheim 1972). Normal pennaceous flight feathers from enantiornithines do not exhibit the same degree of flexion in amber, except for at their very tips (Xing et al. 2016a, 2017). Although RDFs display asymmetry, their microstructure indicates an ornamental role. At most, the barbules in the RDFs have reduced hooklets that would not form strong connections between barbs and produce rigid vanes (Figs. 3c and 5f). Coupled with their $\mathrm{C}$-shaped or flattened rachis profiles, poor closure of the vanes would have yielded feathers with limited aerodynamic properties but perhaps effective as lightweight tail streamers. The lack of pith, and a rachis that only forms three-quarters of a cylinder in cross-section may have been bolstered by thickened sections of rachis near the rachidial ridge and posterior margins of the laminae, but fully testing the functional constraints on these feathers is beyond the scope of the present study.

In addition to the evidence from compression fossils (e.g., O'Connor et al. 2012; Wang et al. 2014), structural evidence from amber supports RDFs as a means of visual display. In modern birds, ornamental feathers are colorful and play an important role in behaviors such as courtship (Hill 2006). The high proportion of specimens in amber that are recovered as pairs with no sign of an adjacent corpse, or with surrounding feather patterns that seem to indicate a striking contact with the resin surface, would suggest that these feathers are easily removed. The apparent ease of removal and muted colors observed in amber RDFs may indicate a sacrificial role in defense, as well as usefulness in visual signaling (Peters and Peters 2009). The reduced amount of material involved in building an elongate RDF with an open and thin-walled rachis may have helped to reduce the energetic costs of producing feathers that were in many cases as long as the total body length of their bearers (Carvalho et al. 2015). One caveat associated with easy removal is that it may limit the usefulness of RDFs in recognizing the sexes of compression fossils, assuming that RDFs were a dimorphic feature within any of their bearers (Chiappe et al. 2008; Peters and Peters 2009; O'Connor et al. 2012).

\subsection{Evolutionary development}

The unusual morphology of RDFs can be accommodated within accepted follicle collar development patterns (Prum 1999), but requires greater variation in the production of new tissue than in modern birds. Production must halt along the posterior margin of the follicle in RDFs to create feathers that have an open rachis on their ventral surface. In the amber sample set that is currently available, the laminae appear to remain open all the way to the follicle (e.g., Fig. 4f, i), but in situ feathers are required to observe if the follicle collar is closed at the skin surface. Based on comparison between well-preserved RDFs and normal flight feathers in Early Cretaceous compression fossils, RDFs were inferred to represent secondarily modified normal pennaceous flight feathers (O'Connor et al. 2012; Wang et al. 2014). While the fact they are pennaceous feathers is not debatable at this point, the detailed morphology gleaned from amber specimens reveals striking differences that reopen the question of whether this morphotype evolved from a normal pennaceous feather, in which the rachis is hollow and pith filled, or whether it has an independent evolutionary pathway. Based on the normal rachis morphology of the remiges in Burmese amber enantiornithines, it is likely that the medial stripe observed in RDFs and that in unmodified remiges and rectrices in compression fossils is not homologous. If homologous, it may suggest that the superficially 'modern' remiges and rectrices in Jehol ornithothoracines in fact represent a primitive stage in feather evolution. Ultimately, this question will require additional specimens with exceptional preservation to address.

\subsection{Habitat evidence}

Many of the amber specimens in this study have been polished into thin pieces that are yellow and very clear. However, some samples are very rich in syninclusions, such as particulates, trichomes, insects and botanical inclusions. DIP-V-17109, for example, is very rich in insect and particulate inclusions (Fig. 5a). DIP-V-16186 and 
DIP-V-17153 contain more diagnostic plant remainsfern sporangia with the "catapult" structure characteristic of the polypod ferns. These syninclusions provide some associations between the RDF feather inclusions and plant groups beyond the trees within Araucariaceae or Dipterocarpaceae that are thought to have produced the resin (Ross et al. 2010). However, there are no consistent indicators for a particular habitat or height within the forest canopy (e.g., 'litter amber'; Perrichot 2004) found among the RDF sample set.

\section{Conclusions}

Cretaceous birds retained numerous primitive feather morphotypes, most of which are better understood through preservation in amber. The new RDFs preserved in three dimensions within amber clearly indicate that this feather type had an open rachis much different from the rachises found in modern bird flight feathers. An open rachis may have been a cost-saving measure in the production of feathers that could grow as long as their bearers. The RDF morphotype may also have evolved specifically to create streamers that were elongate but lightweight. It is possible that these feathers represent a primitive holdover (prior to the development of a full rachis), or they may represent a secondary loss of the tubular rachis. Notably, flexion was not previously inferred from compression fossils found in rocks of Early Cretaceous age (based on the straight and unbent preservation of the feathers in all known specimens in the Jehol Biota). This may suggest that the flexibility is a derived feature, or that the feathers are only able to flex ventrally under significant force. The relative abundance of paired RDFs in amber suggests that many of the samples in Burmese amber were originally paired tail feathers, and that these were plucked without the entire bird becoming ensnared in resin. If the feathers were easy to remove, their role may have gone beyond visual signalling, also serving as a defensive decoy, and their presence or absence in compression fossils should be used as a sexual indicator with caution.

\section{Acknowledgements}

Christopher Somers (University of Regina), Ray Poulin and Danae Frier (RSM) for discussions and research support; and Nathan Gerein (University of Alberta) for SEM assistance.

\section{Funding}

We thank National Natural Science Foundation of China (41772008), Fundamental Research Funds for the Central Universities (2652017215), National Geographic Society, U.S.A. (EC0768-15), Natural Sciences and Engineering Research Council, Canada (2015-00681), RSM and Paul Riegert scholarships (to P.C.) for support.

\section{Availability of data and materials}

All data generated or analyzed during this study are included in this published article.
Authors' contributions

$L X, P C, J O$, and RCM designed the project, performed the research, and wrote the manuscript. All the authors contributed to reviewing the manuscript.

\section{Competing interests}

The authors declare that they have no competing interests.

\section{Publisher's Note}

Springer Nature remains neutral with regard to jurisdictional claims in published maps and institutional affiliations.

\begin{abstract}
Author details
${ }^{1}$ State Key Laboratory of Biogeology and Environmental Geology, China University of Geosciences (Beijing), Beijing 100083, China. ${ }^{2}$ School of the Earth Sciences and Resources, China University of Geosciences (Beijing), Beijing 100083, China. ${ }^{3}$ Royal Saskatchewan Museum, Regina, Saskatchewan S4P 4W7, Canada. ${ }^{4}$ Biology Department, University of Regina, Regina, Saskatchewan S4S 0A7, Canada. ${ }^{5}$ Department of Ecology \& Evolutionary Biology, University of Kansas, Lawrence, Kansas 66045, USA. ${ }^{6}$ Institute of Vertebrate Paleontology and Paleoanthropology, Chinese Academy of Sciences, Beijing 100044, China.
\end{abstract}

Received: 17 October 2018 Accepted: 28 November 2018

Published online: 14 December 2018

\section{References}

Bleiweiss, R. 1987. Development and evolution of avian racket plumes: fine structure and serial homology of the wire. Journal of Morphology 194: 23-39.

Bonser, R.H.C., and P.P. Purslow. 1995. The Young's modulus of feather keratin. Journal of Experimental Biology 198: 1029-1033.

Canvalho, IS., F.E. Novas, F.L. Agnolín, M.P. Isasi, F.l. Freitas, and J.A. Andrade. 2015. A Mesozoic bird from Gondwana preserving feathers. Nature Communications 6: 7141.

Chen, P., Z. Dong, and S. Zhen. 1998. An exceptionally well-preserved theropod dinosaur from the Yixian formation of China. Nature 391: 147-152.

Chiappe, L.M., J. Marugán-Lobón, S. Ji, and Z. Zhou. 2008. Life history of a basal bird: Morphometrics of the early cretaceous Confuciusornis. Biology Letters 4 : 719-723.

Delclòs, X., A. Arillo, E. Peñalver, E. Barrón, C. Soriano, R. López Del Valle, E. Bernárdez, C. Corral, and V.M. Ortuño. 2007. Fossiliferous amber deposits from the cretaceous (Albian) of Spain. Comptes Rendus Palevol 6: 135-149.

Dove, C.J. 2000. A descriptive and phylogenetic analysis of plumulaceous feather characters in Charadriiformes. Ornithology Monographs 51: 1-63.

Grimaldi, D.A., and G.R. Case. 1995. A feather in amber from the Upper Cretaceous of New Jersey. American Museum Novitates 3126: 1-6.

Grimaldi, D.A., M.S. Engel, and P.C. Nascimbene. 2002. Fossiliferous Cretaceous amber from Myanmar (Burma): its rediscovery, biotic diversity, and paleontological significance. American Museum Novitates 3361: 1-71.

Hill, G.E. 2006. Female mate choice for ornamental coloration in birds. In Bird coloration: function and evolution, ed. G.E. Hill and K.E. McGraw, 137-200. Cambridge: Harvard University Press.

Hu, H., J.K. O'Connor, and Z. Zhou. 2015. A new species of Pengornithidae (Aves: Enantiornithes) from the Lower Cretaceous of China suggests a specialized scansorial habitat previously unknown in early birds. PLoS One 10: e0126791.

Ji, Q., P.J. Currie, M.A. Norell, and J. Shu-An. 1998. Two feathered dinosaurs from northeastern China. Nature 393: 753-761.

Ji, Q., and S.-A. Ji. 1996. On the discovery of the earliest fossil bird in China (Sinosauropteryx gen. nov.) and the origin of birds. Chinese Geology 233: 30-33.

Lucas, A.M., and P.R. Stettenheim. 1972. Avian anatomy integument. Washington, D.C.: United States Department of Agriculture.

McKellar, R.C., B.D.E. Chatterton, A.P. Wolfe, and P.J. Currie. 2011. A diverse assemblage of Late Cretaceous dinosaur and bird feathers from Canadian amber. Science 333: 1619-1622.

McKittrick, J., P. Chen, S. Bodde, W. Yang, E. Novitskaya, and M.A. Meyers. 2012. The structure, functions, and mechanical properties of keratin. The Journal of the Minerals, Metals \& Materials Society 64: 449-468.

O'Connor, J.K., L.M. Chiappe, C.M. Chuong, D.J. Bottjer, and H. You. 2012 Homology and potential cellular and molecular mechanisms for the development of unique feather morphologies in early birds. Geosciences 2: 157-177. 
Peñalver, E., A. Arillo, X. Delclòs, D. Peris, D.A. Grimaldi, S.R. Anderson, P.C. Nascimbene, and R. Pérez-de la Fuente. 2017. Ticks parasitised feathered dinosaurs as revealed by Cretaceous amber assemblages. Nature Communications 8: 1924.

Perrichot, V. 2004. Early Cretaceous amber from South-Western France: insight into the Mesozoic litter fauna. Geologica Acta 2: 9-22.

Perrichot, V., L. Marion, D. Néraudeau, R. Vullo, and P. Tafforeau. 2008. The early evolution of feathers: Fossil evidence from Cretaceous amber of France. Proceedings of the Royal Society of London B, Biological Sciences 275: 1917-1202.

Peters, W.S., and D.S. Peters. 2009. Life history, sexual dimorphism and 'ornamental' feathers in the Mesozoic bird Confuciusornis sanctus. Biology Letters 5: 817-820.

Prum, R.O. 1999. Development and evolutionary origin of feathers. Journal of Experimental Zoology 285: 291-306

Ross, A., C. Mellish, P. York, and B. Crighton. 2010. Burmese amber. In Biodiversity of fossils in amber from the major world deposits, ed. D. Penney, 208-235. Manchester: Siri Scientific Press.

Schlee, D., and W. Glöckner. 1978. Bernstein: Bernsteine und Berstein-Fossilien. Stuttgarter Beiträge zur Naturkunde - Serie B 8: 1-72.

Shi, G., D.A. Grimaldi, G.E. Harlow, J. Wang, J. Wang, M. Yang, W. Lei, Q. Li, and X. Li. 2012. Age constraint on Burmese amber based on U-Pb dating of zircons. Cretaceous Research 37: 155-163.

Thomas, D.B., P.C. Nascimbene, C.J. Dove, and H.F. James. 2014. Seeking carotenoid pigments in amber-preserved fossil feathers. Scientific Reports 4: 5226.

van der Reest, A.J., A.P. Wolfe, and P.J. Currie. 2016. A densely feathered ornithomimid (Dinosauria: Theropoda) from the Upper Cretaceous Dinosaur Park Formation, Alberta, Canada. Cretaceous Research 58: 108-117.

Wang, M., X. Zheng, J.K. O'Connor, G.T. Lloyd, X. Wang, Y. Wang, X. Zhang, and Z. Zhou. 2015. The oldest record of Ornithuromorpha from the Early Cretaceous of China. Nature Communications 6: 6987.

Wang, X., J.K. O'Connor, X. Zheng, M. Wang, H. Hu, and Z. Zhou. 2014. Insights into the evolution of rachis dominated tail feathers from a new basal enanthiornine (Aves: Ornithothoraces). Biological Journal of the Linnean Society 113: 805-819.

Xing, L., R.C. McKellar, M. Wang, M. Bai, J.K. O'Connor, M.J. Benton, J. Zhang, Y. Wang, K. Tseng, M.G. Lockley, G. Li, W. Zhang, and X. Xu. 2016a. Mummified precocial bird wings in mid-Cretaceous Burmese amber. Nature Communications 7: 12089

Xing, L., R.C. McKellar, X. Xu, G. Li, M. Bai, W.S.I.V. Persons, T. Miyashita, M.J. Benton, J. Zhang, A.P. Wolfe, Q. Yi, K. Tseng, H. Ran, and P.J. Currie. 2016b. A feathered dinosaur tail with primitive plumage trapped in mid-Cretaceous amber. Current Biology 26: 3352-3360.

Xing, L., J.K. O'Connor, R.C. McKellar, L.M. Chiappe, K. Tseng, G. Li, and M. Bai. 2017. A mid-Cretaceous enantiornithine (Aves) hatchling preserved in Burmese amber with unusual plumage. Gondwana Research 49: 264-277.

Xu, X., X. Zheng, and H. You. 2010. Exceptional dinosaur fossils show ontogenetic development of early feathers. Nature 464: 1338-1341.

Xu, X., Z. Zhou, R. Dudley, S. Mackem, C.-M. Chuong, G.M. Erickson, and D.J. Varrichio. 2014. An integrative approach to understanding bird origins. Science 346: 1253293.

Zhang, F., and Z. Zhou. 2000. A primitive enantiornithine bird and the origin of feathers. Science 290: 1955-1959.

Zhang, F., Z. Zhou, and G. Dyke. 2006. Feathers and 'feather-like' integumentary structures in Liaoning birds and dinosaurs. Geological Journal 41: 395-404.

Zhang, F.C., Z.H. Zhou, X. Xu, X.L. Wang, and C. Sullivan. 2008. A bizarre Jurassic maniraptoran from China with elongate ribbon-like feathers. Nature 455: $1105-1108$

Zhang, Z., Z. Zhou, and M.J. Benton. 2008. A primitive confuciusornithid bird from China and its implications for early avian flight. Science in China Series D: Earth Sciences 51: 625-639.

Zheng, X.T., H.L. You, X. Xu, and Z.M. Dong. 2009. An Early Cretaceous heterodontosaurid dinosaur with filamentous integumentary structures. Nature 458: 333-336.

\section{Submit your manuscript to a SpringerOpen ${ }^{\circ}$ journal and benefit from:}

- Convenient online submission

Rigorous peer review

- Open access: articles freely available online

- High visibility within the field

- Retaining the copyright to your article

Submit your next manuscript at $\boldsymbol{\nabla}$ springeropen.com 